\title{
Consumo, cinética digestiva e digestibilidade de nutrientes em equinos atletas alimentados com dietas contendo óleo de soja ${ }^{1}$
}

\author{
Fernanda Nascimento de Godoi ${ }^{2}$, Fernando Queiroz de Almeida ${ }^{3}$, Eloisa de Oliveira Simões \\ Saliba ${ }^{4}$, Henrique Torres Ventura ${ }^{5}$, Almira Biazon França ${ }^{6}$, Liziana Maria Rodrigues ${ }^{6}$
}

\author{
1 Pesquisa financiada pelo CNPq/FAPERJ/EsEqEX. \\ 2 Programa de Pós-graduação em Zootecnia - UFRRJ. Bolsista da CAPES. \\ 3 Instituto de Veterinária - UFRRJ. Bolsista Pesquisador CNPq. \\ ${ }^{4}$ Escola de Veterinária - UFMG. Bolsista Pesquisador CNPq. \\ ${ }^{5}$ Graduação em Zootecnia da UFRRJ - Bolsista Iniciação Científica - FAPERJ. \\ ${ }^{6}$ Graduação em Zootecnia da UFRRJ - Bolsista Iniciação Científica - PIBIC/CNPq.
}

RESUMO - Objetivou-se avaliar o consumo, a cinética digestiva e a digestibilidade de nutrientes em equinos consumindo rações suplementadas com óleo de soja. Foram utilizados 15 equinos em delineamento experimental inteiramente casualizado com três dietas e cinco repetições. As dietas experimentais foram formuladas a partir de uma dieta controle (sem inclusão de óleo de soja) acrescida 8,5\% ou 19,5\% de óleo de soja. O ensaio teve duração de 34 dias: 30 de adaptação dos equinos às dietas e quatro de coleta de fezes. A cinética da fase líquida da digesta no trato digestivo foi estimada pela LIPE ${ }^{\circledR}$ (lignina isolada, purificada e enriquecida) na forma líquida. A LIPE ${ }^{\circledR}$ foi fornecida no $30^{\circ}$ dia, em dose única, e as amostras de fezes foram coletadas nos tempos $0,2,4,8,12,16,20,24,30,36,42,48,54,60,66,72$ e 78 horas após o fornecimento. O consumo de matéria seca das dietas reduziu com a inclusão de óleo de soja. O coeficiente de digestibilidade aparente do extrato etéreo aumentou nas dietas hiperlipidêmicas, enquanto o de digestibilidade da celulose reduziu com a inclusão de 19,5\% de óleo de soja. O coeficiente de digestibilidade dos demais nutrientes, exceto o de proteína bruta, e a cinética da digesta no trato gastrointestinal não foram alterados. A inclusão de óleo de soja em dietas práticas para equinos possibilita reduzir o consumo de matéria seca e aumentar a concentração energética, desejável em equinos atletas.

Palavras-chave: cavalos, dietas hiperlipidêmicas, digestão, fibra, lipídeos

\section{Intake, digestive kinetics and nutrient digestibility in athletic horses fed diets with soybean oil}

\begin{abstract}
The objective of this study was to evaluate intake, digestive kinetics and nutrient digestibility in horses fed diets supplemented with soybean oil inclusion. Fifteen horses were used in a randomized complete design with three diets and five replications. The experimental diets were formulated from a control diet (without soybean oil) with the addition of 8.5\% and 19.5\% soybean oil. The experiment lasted for 34 days, 30 days for the horses to adapt to the diets and four days for feces collection. The kinetics of the liquid phase of the digesta in the digestive tract was estimated by LIPE ${ }^{\circledR}$ (Purified Enriched Isolated Lignin) in liquid form. LIPE ${ }^{\circledR}$ was given on the $30^{\text {th }}$ day, in a single dose, and the feces samples were collected at $0,2,4,8,12,16,20,24,30,36,42,48,54,60,66,72$ and 78 hours after administration. Dry matter intake of the diets decreased with soybean inclusion. The apparent digestibility coefficient of the ether extract increase in the high fat diets, while the cellulose digestibility decreased with the inclusion of $19.5 \%$ soybean oil. The coefficient of digestibility of the other nutrients, except crude protein, and the kinetics of the digesta in the gastrointestinal tract were not altered. Including soybean oil in practical diets for horses enables dry matter intake reduction and increase in the energetic concentration, which is desirable in athletic horses.
\end{abstract}

Key Words: horses, high fat diet, digestion, fiber, lipids

\section{Introdução}

Os equinos de alto desempenho desportivo são geralmente alimentados com dietas com elevadas quantidades de grãos visando suprir às exigências energéticas. Todavia, a limitada capacidade digestiva e os elevados teores de amido nas dietas comprometem a digestão dos carboidratos não-fibrosos no intestino delgado, o que pode aumentar o aporte de carboidratos rapidamente fermentáveis no ceco-cólon e contribuir para complicações digestivas e 
metabólicas, como cólicas, endotoxemias e laminites. Esses fatos sugerem a necessidade de se evitar a sobrecarga do trato gastrointestinal com a ingestão demasiada de grãos pelos equinos e reduzir os riscos de distúrbios digestivos, proporcionando aumento no desempenho atlético.

Uma característica importante dos óleos e das gorduras é o aumento da densidade energética das dietas sem aumento da quantidade de alimentos consumida, com redução dos riscos de algumas desordens digestivas, além de melhorar a tolerância à glicose por diminuir o pico da resposta glicêmica pós-prandial. O consumo de óleo também aumenta ou mantém a concentração da glicose sanguínea durante exercícios prolongados, retarda o acúmulo de ácido lático durante os exercícios anaeróbicos e diminui o perfil calórico e, além de fornecer ácidos graxos essenciais, aumenta a absorção de vitaminas lipossolúveis e reduz a puverulência das rações (Frape, 2004).

Embora a maioria dos alimentos contenha apenas 2 a 6\% de gordura, os equinos podem utilizar até $20 \%$ de gorduras adicionadas na dieta e 30\% na ração concentrada, sem efeitos adversos (Lewis, 1995). Existem controvérsias sobre o uso de óleos e gorduras na alimentação dos equinos e os efeitos sobre a digestibilidade da fibra e seus componentes. Alguns autores (Manzano et al., 1995; Bush et al., 2001; Kronfeld et al., 2004) não observaram efeito associativo da adição de lipídios na dieta com a digestibilidade da fibra, entretanto outros autores (Jansen et al., 2000; 2002; 2007) observaram que a inclusão de elevadas quantidades de óleo na dieta reduz a digestibilidade dos constituintes da fibra.

Neste trabalho, objetivou-se avaliar o consumo, a cinética digestiva e a digestibilidade aparente dos nutrientes em equinos atletas mantidos com dietas suplementadas com óleo de soja.

\section{Material e Métodos}

O experimento foi conduzido na Escola de Equitação do Exército (EsEqEx) e as análises, no Laboratório de Pesquisas em Saúde Equina (EQUILAB) do Instituto de Veterinária e no Laboratório de Bromatologia Animal do Instituto de Zootecnia da Universidade Federal Rural do Rio de Janeiro no período de junho a julho de 2006. Durante o período experimental, as médias das temperaturas máxima e mínima foram de $28,23 \pm 3,26^{\circ} \mathrm{C}$ e $15,44 \pm 1,41^{\circ} \mathrm{C}$, respectivamente, e a pluviosidade, de $0,48 \pm 1,36 \mathrm{~mm}$, segundo dados do Instituto Nacional de Meteorologia, $6^{\circ}$ Distrito.

O ensaio teve duração de 34 dias, sendo 30 dias de adaptação dos equinos às dietas e quatro dias de coleta de fezes. O delineamento experimental utilizado foi o inteiramente casualizado com três tratamentos (dietas) e cinco repetições (animais).

Foram utilizados 15 equinos mestiços das raças Brasileiro de Hipismo, Puro-Sangue Inglês e Hannoveriano, com média de idade de 7,6 \pm 3,5 anos, peso médio de $457 \pm$ $31 \mathrm{~kg}$ e escore corporal variando de 4,5 a 5, segundo metodologia descrita por Henneke et al. (1983). Os animais foram pesados semanalmente e avaliados quanto ao escore corporal. Os animais foram exercitados diariamente em atividade moderada, com duração de 1,5 hora, nos andamentos passo, trote e galope.

As dietas experimentais foram definidas como: dieta sem inclusão de óleo de soja (controle) composta de concentrado comercial, farelo de soja, sal comum e feno de coastcross; dieta com inclusão de 8,5\% de óleo de soja, composta por concentrado comercial, farelo de soja, óleo de soja, mistura mineral, sal comum e feno de coastcross; dieta com inclusão de 19,5\% de óleo de soja composta por concentrado comercial, farelo de soja, óleo de soja, mistura mineral, sal comum e feno de coastcross.

As dietas foram formuladas (Tabela 1) segundo as exigências nutricionais de equinos adultos e de acordo com a atividade física e peso dos animais (NRC, 1989).

O óleo de soja foi incluído nas dietas dos equinos de forma gradual para adaptação do trato digestivo. Foram utilizadas quatro etapas de adaptação dos equinos à dieta com inclusão de 8,5\% de óleo de soja, com inclusão de 15 , 43, 70 e 100\% do total de óleo de soja, de 730 mL, em média. E, na dieta com de 19,5\% de óleo de soja, foram necessárias cinco etapas de adaptação, com inclusão de 10, 30, 57, 75 e 100\% do total de óleo de soja, de 1.440 mL, em média. Cada etapa durou no mínimo cinco dias.

O concentrado foi parcialmente retirado nas dietas hiperlipidêmicas (Tabela 2) de acordo com a inclusão do óleo de soja e com o aumento da energia dietética, com redução nas quantidades de feno de coastcross aos equinos, visando manter a mesma relação de concentrado:volumoso, em todas as dietas. A relação concentrado:volumoso na dieta foi de 67:33, na base da matéria seca. O farelo de soja foi acrescentado nas dietas para manter a relação $40 \mathrm{~g}$ de PB/Mcal energia digestível (NRC, 1989).

As quantidades de ração concentrada, feno, farelo de soja, mistura mineral e sal comum foram pesadas e o óleo de soja mensurado diariamente antes do fornecimento aos animais. O óleo de soja, o farelo de soja, a mistura mineral e o sal comum foram adicionados no momento do fornecimento da ração concentrada. A ração foi fornecida diariamente, em cinco vezes, o concentrado, três vezes, em frações iguais, às 4 h, 13 h e 20 h e feno de capim 
Tabela 1 - Composição nutricional dos ingredientes das dietas com base na matéria seca

\begin{tabular}{|c|c|c|c|c|}
\hline \multirow[t]{2}{*}{ Item } & \multicolumn{4}{|c|}{ Ingrediente } \\
\hline & Concentrado & Feno de Coastcross & Farelode soja & Óleo de soja ${ }^{1}$ \\
\hline Matéria seca (\%) & 90,63 & 90,02 & 89,23 & 99,60 \\
\hline Matéria orgânica (\%) & 87,19 & 95,70 & 91,88 & 99,60 \\
\hline Proteína bruta (\%) & 12,97 & 4,66 & 53,99 & 0,00 \\
\hline Extrato etéreo (\%) & 7,05 & 0,99 & 0,94 & 99,60 \\
\hline Fibra em detergente neutro (\%) & 42,31 & 78,94 & 13,41 & 0,00 \\
\hline Fibra em detergente ácido (\%) & 14,16 & 40,63 & 10,83 & 0,00 \\
\hline Celulose (\%) & 7,45 & 29,41 & 3,26 & 0,00 \\
\hline Hemiceluloses (\%) & 31,06 & 42,56 & 2,89 & 0,00 \\
\hline Lignina (\%) & 5,20 & 9,36 & 8,97 & 0,00 \\
\hline Energia bruta (Mcal/kg MS) & 4,18 & 4,30 & 4,64 & 9,33 \\
\hline
\end{tabular}

1 Segundo Rostagno (2005).

Tabela 2 - Composição percentual dos ingredientes e composição nutricional das dietas, com base na matéria seca

\begin{tabular}{|c|c|c|c|}
\hline \multirow[t]{2}{*}{ Item } & \multicolumn{3}{|c|}{$\begin{array}{c}\text { Dieta com inclusão de } \\
\text { óleo de soja }\end{array}$} \\
\hline & $0 \%$ & $8,5 \%$ & $19,5 \%$ \\
\hline Concentrado (\%) & 65,5 & 47,1 & 25,8 \\
\hline Farelo de soja (\%) & 0,9 & 10,0 & 20,0 \\
\hline Óleo de soja (\%) & 0,0 & 8,5 & 19,5 \\
\hline Feno de Coastcross (\%) & 33,0 & 33,0 & 33,0 \\
\hline Sal comum (\%) & 0,6 & 0,7 & 0,8 \\
\hline Mistura mineral ${ }^{1}(\%)$ & 0,0 & 0,7 & 0,9 \\
\hline Total & 100 & 100 & 100 \\
\hline Matéria seca (\%) & 90,48 & 91,17 & 92,05 \\
\hline Matéria orgânica (\%) & 89,46 & 90,42 & 91,83 \\
\hline Proteína bruta (\%) & 10,51 & 13,05 & 15,72 \\
\hline Extrato etéreo (\%) & 4,95 & 12,20 & 21,75 \\
\hline Fibra em detergente neutro (\%) & 53,83 & 47,34 & 39,46 \\
\hline Fibra em detergente ácido (\%) & 22,75 & 21,17 & 19,14 \\
\hline Celulose (\%) & 14,19 & 13,58 & 12,74 \\
\hline Hemiceluloses (\%) & 30,64 & 25,80 & 20,10 \\
\hline 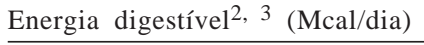 & 23,62 & 23,20 & 23,30 \\
\hline \multicolumn{4}{|c|}{ 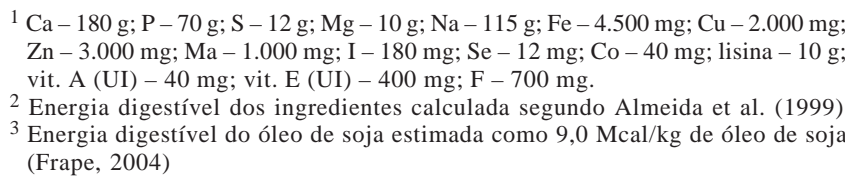 } \\
\hline
\end{tabular}

coastcross (Cynodon dactilon) fornecido duas vezes, em frações iguais, às $11 \mathrm{~h}$ e $16 \mathrm{~h}$, segundo rotina de manejo alimentar da unidade militar.

Os coeficientes de digestibilidade aparente dos nutrientes das dietas foram estimados por meio do método de coleta total de fezes. Os equinos foram alojados em baias individuais de $2,5 \mathrm{~m} \times 2,5 \mathrm{~m}$, com piso de alvenaria, mantidas sempre limpas e secas, providas de comedouros e bebedouros. Os animais permaneceram nas baias durante todo o período de coleta de fezes, exercitando-se a passo, uma vez ao dia durante dez minutos, e observados para averiguar a excreção fecal.

As fezes foram coletadas no piso das baias imediatamente após a defecação, durante 24 horas, ao longo dos quatro dias de coleta. As fezes foram armazenadas em sacos plásticos individuais e, a cada 6 horas, foram pesadas homogeneizadas, para retirada de uma amostra referente a $10 \%$ do peso, e armazenadas em sacos plásticos individuais a $-18^{\circ} \mathrm{C}$. Ao término de cada dia de coleta, as amostras foram homogeneizadas. Uma amostra composta diária foi retirada de cada animal e, em seguida, armazenada a $-18^{\circ} \mathrm{C}$.

Ao término do ensaio, as amostras diárias de cada animal foram descongeladas à temperatura ambiente $\mathrm{e}$ homogeneizadas para retirada de uma amostra composta. As amostras compostas foram pré-secas em estufa de ventilação forçada a $55^{\circ} \mathrm{C}$, durante 72 horas, moídas a $2 \mathrm{~mm}$ e acondicionadas em sacos plásticos até as análises.

Nas amostras de alimentos, sobras e fezes, foram determinados os teores de matéria seca (MS), matéria mineral (MM), proteína bruta (PB), extrato etéreo (EE), energia bruta (EB), hemiceluloses (HEM), celulose (CEL) e lignina (LIG), segundo metodologia descrita por Silva \& Queiroz (2002). As concentrações de fibra em detergente neutro (FDN) e fibra em detergente ácido (FDA) foram determinadas segundo Van Soest et al. (1991).

Os coeficientes de digestibilidade aparente dos nutrientes foram calculados de acordo com a seguinte equação:

$\mathrm{CD}=\underline{\text { MS consumida }} \times \underline{(\% \text { nutriente na dieta })-\mathrm{MS} \text { fezes }} \times \underline{(\% \text { nutriente nas fezes })} \times 100$ MS consumida $\times(\%$ nutriente dieta $)$

Para avaliar a cinética da fase líquida da digesta no trato digestivo foi utilizado, de forma inédita, o indicador externo LIPE ${ }^{\circledR}$ (lignina purificada e enriquecida), na forma líquida, desenvolvido no Departamento de Zootecnia da Escola de Veterinária da Universidade Federal de Minas Gerais e no Departamento de Química do Instituto de Ciências Exatas da UFMG.

A LIPE ${ }^{\circledR}$ foi fornecida no $30^{\circ}$ dia do período de adaptação, em dose única, por via oral, com auxílio de uma seringa, na quantidade de $1 \mathrm{~g}$ diluído em $50 \mathrm{~mL}$ de água, às $13 \mathrm{~h}$, antes da ração concentrada. As amostras de fezes, de aproximada- 
mente $200 \mathrm{~g}$ cada, foram coletadas diretamente da ampola retal nos tempos $0,2,4,8,12,16,20,24,30,36,42,48,54$, 60, 66, 72 e 78 horas após o fornecimento do indicador, segundo metodologia descrita por Cuddeford et al. (1992), e armazenadas em sacos plásticos a $-18^{\circ} \mathrm{C}$.

As amostras de fezes foram pré-secas em estufa de ventilação forçada a $55^{\circ} \mathrm{C}$ por 72 horas e moídas a $1 \mathrm{~mm}$. Em seguida, foram misturadas em brometo de potássio a $1 \%$ e submetidas às leituras das concentrações em espectroscopia no infravermelho. As concentrações de LIPE $^{\circledR}$ foram calculadas pela razão logarítmica das bandas espectrais entre os comprimentos de onda $\lambda 1$ (1050 ๆm) e $\lambda 2$ (1650 ๆm) (Saliba et al., 2003).

O tempo médio de retenção (TMR) da fase líquida da digesta no trato digestivo foi calculado segundo a equação proposta por Faichney (1975): TMR (horas) $=\Sigma \mathrm{mix}$ ti $/ \Sigma \mathrm{mi}$; em que: $\mathrm{mi}=$ quantidade de indicador excretado no $\mathrm{i}$ intervalo de tempo; $\mathrm{ti}=$ intervalo de tempo entre fornecimento do indicador e i tempo de coleta fecal.

A taxa de passagem (TxP) da fase líquida da digesta no trato digestivo foi estimada como o inverso da TMR: $\operatorname{TxP}\left(\% \mathrm{~h}^{-1}\right)=1 / \mathrm{TMR}$.

O tempo de trânsito (TT) da fase líquida da digesta no trato digestivo foi considerado como o intervalo entre o fornecimento do indicador aos equinos e o aparecimento inicial nas fezes (Van Weyenberg et al., 2006).

Os valores do consumo, da cinética digestiva e dos coeficientes de digestibilidade dos nutrientes foram submetidos à análise de variância e comparados pelo teste de Student-Newman Keuls a 5\% de probabilidade. As análises estatísticas foram realizadas pelo SAEG - Sistema de Análises Estatísticas e Genéticas (UFV, 2007).

\section{Resultados e Discussão}

Os valores médios de peso vivo inicial e final dos animais foram de $456,5 \pm 31$ e $478,8 \pm 35 \mathrm{~kg}$, respectivamente.
Todos os equinos apresentaram ganho de peso, em média de $0,54 \mathrm{~kg} / \mathrm{dia}$, durante o período experimental, independentemente da dieta utilizada, favorecendo a manutenção do escore corporal.

O óleo de soja supriu em 15,3 e 30,3\% a energia bruta nas dietas hiperlipidêmicas, em relação à dieta controle, correspondendo a 5,8 e 11,5 Mcal nas dietas com inclusão de 8,5 e 19,5\% de óleo de soja, respectivamente.

Segundo Hintz (1997), o período de 30 dias de adaptação dos equinos às dietas com inclusão de óleo é adequado para adaptação enzimática no trato digestivo e para que os efeitos nos equinos sejam observados.

A inclusão de óleo de soja nas dietas propiciou a redução significativa do consumo de matéria seca nas dietas hiperlipidêmicas (Tabela 3). O consumo de matéria seca, em percentual do peso vivo, entre os equinos alimentados com as dietas controle e com 8,5 e 19,5\% de inclusão de óleo de soja foi de 1,80; 1,55 e 1,26\% PV, respectivamente. Nas dietas hiperlipidêmicas, os valores foram inferiores ao recomendado pelo NRC (1989), de 1,88\% PV, porém, de acordo com o NRC (2007) pode-se estimar o consumo mínimo de matéria seca em 1,50\% PV.

Outros autores também verificaram que a elevada densidade energética dietética com a adição ou inclusão de óleo nas dietas de equinos reduz o consumo de matéria seca. Marqueze et al. (2001), utilizando dietas com 7,8\% de óleo de soja, observaram consumo de matéria seca de $1,66 \% \mathrm{PV}$, semelhante ao observado por Kronfeld et al. (2004), de 1,60\% PV, em vários ensaios de digestibilidade com dietas hiperlipidêmicas. Mattos et al. (2006) verificaram redução no consumo da matéria seca em equinos alimentados com dietas com 3,1 e 6,8\% de óleo de soja, de 1,74 e 1,6 \% PV, respectivamente. Delobel et al. (2008), avaliando dietas com $8 \%$ de óleo de linhaça para equinos adultos durante 90 dias, com consumo de matéria seca de $1,2 \% \mathrm{PV}$, verificaram que os equinos permaneceram saudáveis durante todo o período.

Tabela 3 - Consumo médio diário dos nutrientes das dietas

\begin{tabular}{|c|c|c|c|c|}
\hline \multirow[t]{2}{*}{ Item } & \multicolumn{3}{|c|}{ Nível de óleo de soja } & \multirow[t]{2}{*}{ CV (\%) } \\
\hline & $0 \%$ & $8,5 \%$ & $19,5 \%$ & \\
\hline Matéria seca (kg) & $9,02 \mathrm{a}$ & $7,11 b$ & $6,15 c$ & 7,4 \\
\hline Proteína bruta (kg) & $0,95 a$ & $0,93 a$ & $0,94 a$ & 11,3 \\
\hline Energia bruta (Mcal/kgMS) & $4,20 c$ & $4,63 b$ & $5,22 \mathrm{a}$ & 7,5 \\
\hline Extrato etéreo (kg) & $0,45 c$ & $0,89 b$ & $1,32 \mathrm{a}$ & 6,1 \\
\hline Celulose (kg) & $1,32 \mathrm{a}$ & $0,97 b$ & $0,76 \mathrm{c}$ & 6,8 \\
\hline Hemiceluloses (kg) & $2,80 \mathrm{a}$ & $1,89 b$ & $1,27 \mathrm{c}$ & 6,7 \\
\hline
\end{tabular}

Médias nas linhas, seguidas por letras iguais, não diferem pelo SNK $(\mathrm{P}>0,05)$.

${ }^{1} \mathrm{PV}=$ peso vivo. 
A redução no consumo de MS e a substituição dos carboidratos não-fibrosos por lipídios são medidas benéficas aos equinos atletas por reduzirem o peso do trato digestivo e os riscos de cólicas ou diarreias e, desse modo, potencializam o melhor desempenho dos equinos (Potter et al., 1992).

O consumo médio de proteína foi de $940 \mathrm{~g}$ PB/dia e não diferiu $(\mathrm{P}>0,05)$ entre as dietas experimentais. Essa quantidade está de acordo com as indicações do NRC (1989), de 944 g/dia para equinos com 478 kg PV, porém, superior ao recomendado pelo NRC (2007), de 734 g PB/dia. Segundo Pagan (2000), um dos aspectos mais importantes a ser considerado na alimentação dos equinos é o conteúdo energético das dietas. Neste estudo, a inclusão dietética do óleo de soja aumentou significativamente a densidade energética das dietas.

Como esperado, o consumo de extrato etéreo aumentou $(\mathrm{P}<0,05)$ com a inclusão de óleo de soja nas dietas, alcançando 1,32 kg na dieta com inclusão de 19,5\% de óleo de soja. Segundo Hintz (1997), são necessários mínimo de $500 \mathrm{~g} /$ dia de gordura suplementar na dieta e aumento gradual de até 1 kg para obtenção de efeitos máximos no desempenho atlético, de modo que o restante da energia dietética é fornecido pelos grãos em quantidade suficiente para aumentar o peso corporal e as reservas de glicogênio. Entretanto, é necessário avaliar as proporções dos demais nutrientes para compor uma dieta balanceada que atenda às exigências dos nutrientes para os equinos.

Os consumos de FDN, FDA, celulose e hemiceluloses reduziram $(\mathrm{P}<0,05)$ com o aumento do nível de óleo de soja. As hemiceluloses e a FDN apresentaram as maiores reduções no consumo nas dietas com 8,5 e 19,5\% de óleo de soja em comparação à dieta controle, de 32,5 e 54,6\% e 30 e 50\%, respectivamente. As reduções no consumo de FDA e celulose foram equivalentes, de 26 e $42 \%$ nas dietas com 8,5 e 19,5\% de inclusão de óleo de soja, respectivamente, em comparação à dieta controle.

A redução no consumo das frações fibrosas está relacionada à menor oferta do alimento volumoso aos equinos nas dietas hiperlipidêmicas, uma vez que todas as dietas tiveram a mesma relação concentrado:volumoso, de 67:33.
Os equinos alimentados com as dietas controle e 8,5\% de inclusão de óleo de soja apresentaram valores médios de consumo de feno de coastcross em 610 e $530 \mathrm{~g}$ MS/100 kg $\mathrm{PV}$, respectivamente. Esses valores estão de acordo com Cunha (1991), que indicou o mínimo adequado de 500 g MS de feno/100 kg de PV. Entretanto, na dieta com maior inclusão de óleo de soja, de 19,5\%, os equinos apresentaram consumo médio de feno de $430 \mathrm{~g}$ MS de feno/100 kg PV.

Hintz \& Cymbaluk (1994) sugerem o mínimo de $120 \mathrm{~g}$ de fibra bruta $/ 100 \mathrm{~kg}$ de $\mathrm{PV}$, o que equivale a $20 \%$ de FDN e $12 \%$ de FDA na dieta, portanto os percentuais de FDN e FDA na dieta com inclusão de 19,5\% de óleo de soja, de 39,4 \% FDN e 19,1\% FDA, estão acima do recomendado por esses autores.

Não houve efeito da inclusão de óleo de soja nas dietas dos equinos atletas no TMR, TxP e TT da fase líquida da digesta $(\mathrm{P}>0,05)$, com valores médios de 35,7 horas, 2,8\%/hora e 7,6 horas, respectivamente (Tabela 4).

Estudos cinéticos do trato digestivo de equinos alimentados com dietas contendo óleos ou gorduras são escassos na literatura. Manzano et al. (1995) utilizando equinos consumindo dietas com $5 \%$ de óleo de soja e 5,5\% de gordura animal, verificaram que não houve efeito significativo na taxa de passagem da fase líquida da digesta, com valor médio de $10,1 \%$ /hora, valor muito superior ao observado neste trabalho, de $2,8 \%$ /hora, e que pode ser atribuído ao manejo alimentar dos equinos, pois esses autores forneceram o concentrado juntamente com o volumoso, duas vezes ao dia, na relação concentrado volumoso de 50:50. Lorenzo-Figueras et al. (2005) não observaram efeito significativo das dietas com 8 e 12,3\% de inclusão de óleo de milho na taxa de esvaziamento gástrico, ao contrário, a dieta sem inclusão de óleo e com maior teor de carboidratos solúveis reduziu o esvaziamento gástrico.

Os valores de tempo médio de retenção e taxa de passagem da fase líquida da digesta em todo o trato digestivo observados nos equinos são similares aos observados por Oliveira et al. (2003), de 33,8 horas e $3,0 \% /$ hora, respectivamente, em equinos consumindo dietas com inclusão de até $60 \%$ de concentrado. No entanto,

Tabela 4 - Valores médios do tempo médio de retenção (TMR), da taxa de passagem (TxP) e do tempo de trânsito (TT) da fase líquida da digesta no trato digestivo de equinos consumindo as dietas

\begin{tabular}{lcccc}
\hline \multirow{2}{*}{ Item } & \multicolumn{3}{c}{ Nível de óleo de soja } & \multirow{2}{*}{ CV (\%) } \\
\cline { 2 - 4 } & $0 \%$ & $8,5 \%$ & $19,5 \%$ & 35,7 \\
Tempo médio de retenção (horas) & $34,3 \mathrm{a}$ & $40,4 \mathrm{a}$ & $32,3 \mathrm{a}$ & 11,8 \\
Taxa de passagem (\%/horas) & $2,9 \mathrm{a}$ & $2,5 \mathrm{a}$ & $3,1 \mathrm{a}$ & 2,8 \\
TT (horas) & $7,3 \mathrm{a}$ & $10,7 \mathrm{a}$ & $4,7 \mathrm{a}$ & 7,6 \\
\hline
\end{tabular}

Médias nas linhas, seguidas por letras iguais, não diferem pelo SNK $(\mathrm{P}>0,05)$. 
Oliveira et al. (2007), avaliando equinos alimentados com dietas com relação concentrado:volumoso de 50\%, observaram valores inferiores de tempo médio de retenção da fase líquida da digesta, de 25,9 horas, equivalendo a taxa de passagem da fase líquida da digesta mais rápida, de $3,9 \% /$ hora.

Pagan et al. (1998) e Drogoul et al. (2001) observaram valores de tempo médio de retenção da fase líquida da digesta similares ao presente trabalho, de 32,5 e 34,9 horas, respectivamente, em equinos alimentados com dietas compostas exclusivamente de volumoso. Todavia, Pimentel et al. (2009) verificou valor médio de tempo médio de retenção da fase líquida da digesta um pouco menor, de 30,7 horas, em equinos alimentados com dietas exclusivas de feno de coastcross.

Os valores da cinética digestiva em equinos supracitados podem ser influenciados pelo peso dos animais, pelo tipo de atividade física dos equinos, pela composição química e quantidade de ingredientes nas dietas, tipo e tamanho das partículas do alimento fornecido, pela quantidade de fibra presente na dieta e pelo nível de consumo dietético (Van Weyenberg et al., 2006).

A inclusão de óleo de soja nas dietas não afetou a digestibilidade aparente da matéria seca $(\mathrm{P}>0,05)$, cujo valor médio foi de $62,6 \%$ (Tabela 5 ). No entanto, Jansen et al. $(2000,2002,2007)$ observaram que a inclusão do óleo de soja reduziu a digestibilidade da matéria seca de forma significativa quando o óleo de soja supriu 37 a $63 \%$ de energia líquida da ração concentrada. Delobel et al. (2008), avaliando dietas com $8 \%$ de óleo de linhaça na ração concentrada de equinos, observaram aumento significativo na digestibilidade da matéria seca, com valores de 66,5\%. Esses resultados contraditórios podem estar relacionados à quantidade de óleo utilizada e ao manejo alimentar.

Neste estudo, a dieta foi fracionada em cinco horários e o volumoso fornecido separadamente da ração concentrada por, no mínimo, 3 horas. Nos estudos conduzidos por Kane et al. (1979) com adição de até 30\% de óleo de milho, por Hughes et al. (1995) adicionando 10\% de gordura animal no concentrado e, por Bush et al. (2001) incluindo até $15 \%$ de óleo de milho nas dietas de equinos, fracionadas duas vezes ao dia, não foram observadas diferenças na digestibilidade da matéria seca. No entanto, Jansen et al. (2000; 2002; 2007) observaram redução no coeficiente de digestibilidade da matéria seca, enquanto Delobel et al. (2008) observaram aumento no coeficiente de digestibilidade da matéria seca, utilizando a dieta fracionada duas vezes ao dia. Outro aspecto a ser considerado é a relação concentrado:volumoso, que foi diferente entre esses trabalhos e variou de dietas exclusivas com concentrado (Kane et al., 1979) até dietas com relação concentrado:volumoso de 30:70 (Jansen et al., 2002). Jansen et al. (2000) utilizaram a relação concentrado:volumoso de 70:30 e Jansen et al. (2007), de 60:40, nas dietas com de óleo de soja.

O coeficiente de digestibilidade aparente da proteína bruta aumentou $(\mathrm{P}<0,05)$ nas dietas com inclusão de $8,5 \mathrm{e}$ 19,5\% de óleo de soja, de 9,8 e 12,8 pontos percentuais em relação à dieta controle, respectivamente. Esse fato pode ser explicado pela inclusão do farelo de soja como fonte de proteína no balanceamento das dietas hiperlipidêmicas e, provavelmente, a proteína do farelo de soja apresenta maior digestibilidade em relação à fonte proteica utilizada na ração concentrada comercial utilizada no experimento.

Segundo o NRC (2007), a digestibilidade da proteína varia de acordo com a fonte proteica, os ingredientes e a relação concentrado:volumoso das dietas. De acordo com Almeida et al. (1998), a proteína do farelo de soja possui elevada digestibilidade, em média de $94,8 \%$, valor similar ao citado no NRC (2007), de 92,2\%.

Hughes et al. (1995) e Julen et al. (1995), avaliando dietas com inclusão de gordura animal e utilizando o farelo de soja no balanceamento das dietas, observaram aumento significativo da digestibilidade da PB.

Tabela 5 - Coeficientes de digestibilidade aparente dos nutrientes das dietas suplementadas com óleo de soja

\begin{tabular}{|c|c|c|c|c|}
\hline \multirow[t]{2}{*}{ Item } & \multicolumn{3}{|c|}{ Nível de óleo de soja } & \multirow[t]{2}{*}{ CV (\%) } \\
\hline & $0 \%$ & $8,5 \%$ & $19,5 \%$ & \\
\hline Matéria seca (\%) & $62,3 a$ & $62,6 a$ & $62,8 \mathrm{a}$ & 8,0 \\
\hline Proteína bruta (\%) & $70,5 b$ & $80,3 a$ & 83,3 a & 6,3 \\
\hline Energia bruta (\%) & $63,0 \mathrm{a}$ & $66,2 \mathrm{a}$ & $67,1 \mathrm{a}$ & 8,1 \\
\hline Extrato etéreo (\%) & $71,8 b$ & $89,7 a$ & $91,2 \mathrm{a}$ & 7,7 \\
\hline Celulose $(\%)$ & $50,1 \mathrm{a}$ & $42,9 a$ & $31,8 \mathrm{~b}$ & 16,8 \\
\hline Hemiceluloses (\%) & $63,2 \mathrm{a}$ & $59,2 \mathrm{a}$ & $51,2 \mathrm{a}$ & 10,6 \\
\hline
\end{tabular}

Médias nas linhas, seguidas por letras iguais, não diferem pelo SNK ( $\mathrm{P}>0,05)$. 
Jansen et al. (2000), Bush et al. (2001), Kronfeld et al. (2004) e Jansen et al. (2007) observaram que a inclusão de óleo ou gorduras em dietas para equinos não afeta o coeficiente de digestibilidade da proteína bruta. Entretanto, Jansen et al. (2002), avaliando dietas para equinos adultos variando somente quanto à fonte energética, à glicose, ao amido ou quanto ao óleo de soja, observaram redução da digestibilidade da proteína bruta, com valores médios de 70,0; 68,9 e 62,5\%, respectivamente.

O coeficiente de digestibilidade aparente da gordura foi de 89,7 e 91,2\% nas dietas com 8,5 e 19,5\% de inclusão de óleo de soja, respectivamente, e diferiu $(\mathrm{P}<0,05)$ do obtido com a controle, de 71,8\%. Estes resultados corroboram os de Jansen et al. (2000) e Kronfeld et al. (2004), que observaram aumento da digestibilidade do extrato etéreo em equinos consumindo dietas hiperlipidêmicas. Esses autores sugeriram que dietas com inclusão de óleos ou gorduras aumentam a concentração de lipídios no intestino delgado, o que estimula o aumento da produção da bile e lipase pancreática, proporcionando aumento na digestão da gordura.

O coeficiente de digestibilidade da energia não foi influenciado $(\mathrm{P}<0,05)$ pela inclusão de óleo de soja na dieta, porém houve aumento nos valores médios, de 4,1 pontos percentuais para a dieta com 19,5\% de inclusão de óleo de soja em relação a dieta controle, aumentando a disponibilidade de energia para os equinos. Esses resultados corroboram os encontrados por Kane et al. (1979), que, utilizando dietas com inclusão do óleo de milho equivalendo a 15 e 30\% da energia digestível da dieta, não observaram diferença na digestibilidade da energia, com valor médio de 73,3\%. Do mesmo modo, Bush et al. (2001), utilizando óleo de milho em dietas de equinos, não observaram diferença significativa na digestibilidade da energia, com valor médio de 54,4\%. Jansen et al. (2000), no entanto, verificaram redução significativa de 7,2 pontos percentuais na digestibilidade da energia nas dietas contendo óleo de soja, equivalente a $37 \%$ da energia líquida da dieta.

Os coeficientes de digestibilidade de celulose reduziram somente nos equinos consumindo a dieta com inclusão de 19,5\% de óleo de soja $(\mathrm{P}<0,05)$. A redução foi de 18,3 e 11,1 pontos percentuais em comparação às dietas controle e com 8,5\% de inclusão de óleo de soja, respectivamente. Jansen et al. (2002) observaram redução na digestibilidade dos componentes da fibra, porém, a maior redução, de 16,7 pontos percentuais, foi verificada no coeficiente de digestibilidade da celulose.

Jansen et al. (2007), avaliando a influência de dietas hiperlipidêmicas na cinética de fermentação in vitro, observaram que os inóculos de ceco, cólon e fezes de equinos que consumiram dietas com inclusão de óleo de soja reduziram a produção de gás da celulose e justificaram que esse fato possa estar relacionado à inibição da atividade da microflora celulolítica, que apresentou redução na quantidade de bactérias de $4,1 \times 10^{6} \mathrm{ufc} / \mathrm{mL}$ para 3,6 × $10^{6} \mathrm{ufc} / \mathrm{mL}$, na dieta com adição de óleo de soja.

Os coeficientes de digestibilidade da FDN, FDA e hemiceluloses não foram influenciados $(\mathrm{P}>0,05)$ pela inclusão do óleo de soja na dieta. Pode-se inferir que a inclusão gradual do óleo de soja favoreceu a adaptação do trato digestivo dos equinos, pois, segundo Kronfeld et al. (2004), as gorduras são completamente digeridas no intestino delgado de equinos sadios, o que pode ser confirmado principalmente pela ausência de efeitos negativos da inclusão do óleo de soja na digestibilidade da FDN e FDA, com valores de 51 e 55\%, respectivamente.

A ausência de efeitos significativos na digestibilidade dos constituintes da fibra em dietas hiperlipidêmicas também foi observada por Kane et al. (1979), que, utilizando óleo de milho em níveis de até 30\% da energia digestível da dieta, verificaram valores médios da digestibilidade da FDA de $24,1 \%$. Bush et al. (2001) adicionaram até 15\% de óleo de milho no concentrado e observaram valores médios do coeficiente de digestibilidade da FDN de 23\%.

No entanto, vários autores (Hughes et al., 1995; Julen et al., 1995; Rammerstorfer et al., 1998), avaliando dietas com inclusão de $10 \%$ de gordura animal e relação concentrado:volumoso de 70:30 até 60:40, observaram aumento significativo no coeficiente de digestibilidade da FDN.

Delobel et al. (2008) observaram aumento significativo na digestibilidade da FDN, de 2,3 pontos percentuais em um período experimental de 90 dias, com relação concentrado:volumoso de $50 \%$ e, sugerem que quando os carboidratos são substituídos por óleo ou gorduras, há redução dos efeitos deletérios da fermentação do amido na digestão da fibra no ceco-cólon, o que justificaria o aumento na digestibilidade de FDN.

Apesar disso, há relatos de redução na digestibilidade aparente dos constituintes da fibra em equinos consumindo elevada quantidade de lipídios. Jansen et al. (2000), avaliando dietas sem e com adição de óleo de soja, equivalente a 37\% da energia líquida da ração concentrada, com relação concentrado:volumoso de 70:30 e 60:40, respectivamente, observaram redução significativa na digestibilidade da FDN, FDA e celulose, com valores médios de 60,8; 50,5; $57,0 \%$ e 54,$6 ; 42,2 ; 50,2 \%$, respectivamente.

Jansen et al. (2002) avaliaram dietas para equinos com três fontes energéticas diferentes (amido, glicose e óleo de soja) e relação concentrado:volumoso de aproximadamente 
50:50, 50:50 e 30:70; respectivamente, observaram que a digestibilidade dos constituintes da fibra nas dietas com inclusão de amido ou glicose não apresentou variações significativas, porém a dieta com inclusão óleo de soja reduziu significativamente os coeficientes de digestibilidade da FDN, FDA e celulose, de 9,4; 13,3 e 16,9 pontos percentuais em relação às outras dietas.

Jansen et al. (2007), utilizando óleo de soja em dietas para equinos equivalendo a 37\% da energia líquida da ração concentrada e relação concentrado:volumoso de 60:40 na dieta hiperlipidêmica e de 50:50 na dieta controle, observaram que a inclusão do óleo interferiu significativamente no coeficiente de digestibilidade da FDN, FDA e celulose, reduzindo os valores, de 78,6 para 69,7\%; de 69,4 para 53,8\%; de 76,6 para 63,6\% nas dietas sem e com adição de óleo de soja, respectivamente.

A quantidade de feno utilizada por Jansen et al. (2000, 2002, 2007) não foi similar entre as dietas com e sem inclusão de óleo de soja, o que proporcionou alterações na relação concentrado:volumoso. Além disso, o volumoso foi fornecido juntamente com a ração concentrada e o óleo. Esse manejo dietético pode ter favorecido o aumento da taxa de passagem no intestino delgado, carreando os lipídios para o intestino grosso, o que poderia reduzir a fermentação microbiana no ceco-cólon e a digestibilidade dos constituintes da fibra nas dietas hiperlipidêmicas.

Neste trabalho, a relação concentrado:volumoso foi mantida de forma similar em todas as dietas e o feno de coastcross foi fornecido separadamente, reduzindo assim a possibilidade de carreamento dos lipídios para o ceco-cólon.

Alterações no consumo de volumoso podem modificar a taxa de passagem da digesta, expondo a microflora presente no intestino grosso a uma mudança na quantidade de substratos fermentáveis e, assim, afetar a digestibilidade aparente dos constituintes da fibra (Beynee \& Hallebeek, 2002). No entanto, Oliveira (2001) não observou diferenças significativas no tempo médio de retenção, na taxa de passagem das fases sólida e líquida da digesta e nos coeficientes de digestibilidade da FDN e FDA em equinos consumindo dietas com 40 a $100 \%$ de volumoso.

Os resultados contraditórios observados na literatura provavelmente estão relacionados a variações nos teores de lipídios, às diferenças em relação aos ingredientes da dieta, especialmente em relação à FDN e FDA.

Palmgren Karlsson et al. (2000) citam que efeitos associativos na digestibilidade dos nutrientes estão relacionados à qualidade e quantidade dos ingredientes das dietas. A disponibilidade dos carboidratos difere entre os tipos de cereais e, igualmente, o percentual dos componentes fibrosos varia entre as diversas forragens e alimentos concentrados, o que pode alterar a fermentação no intestino grosso.

O NRC (2007) relata que as contradições nos resultados da digestibilidade dos constituintes da fibra observadas entre os diversos autores podem estar relacionadas à adaptação inadequada dos equinos aos óleos e às gorduras nas dietas e, ainda relacionadas a um curto período de substituição dos carboidratos rapidamente hidrolisáveis por óleos e gorduras. Kronfeld et al. (2004) sugeriram um período de adaptação às dietas de 4 a 14 dias, em decorrência da quantidade de óleo presente na dieta. A dieta com inclusão de $19,5 \%$ de óleo de soja reduziu o consumo de matéria seca digestível em 1,1 e 0,8 kg em relação à dieta controle e a dieta com 8,5\% de inclusão de óleo de soja, respectivamente (Tabela 6). Isso se deve à menor quantidade da dieta com maior inclusão de óleo consumida pelos animais, pois os coeficientes de digestibilidade aparente da matéria seca não diferiram entre as dietas.

O NRC (1989) e Pagan (2000) sugerem o uso da proteína digestível para avaliar as exigências proteicas do cavalo, uma vez que a digestibilidade varia de acordo com a fonte de proteína e sua concentração na dieta. O consumo de proteína digestível não diferiu $(\mathrm{P}>0,05)$ entre as dietas experimentais, com valor médio diário de $0,7 \mathrm{~kg}$ proteína digestível. O NRC (2007) recomenda o consumo médio de 0,75 a $0,83 \mathrm{~kg} /$ dia para equinos atletas com $500 \mathrm{~kg}$ PV.

Tabela 6 - Valores médios do consumo diário dos nutrientes digestíveis das dietas com diferentes níveis de óleo de soja

\begin{tabular}{|c|c|c|c|c|}
\hline \multirow[t]{2}{*}{ Item } & \multicolumn{3}{|c|}{ Nível de óleo de soja } & \multirow[t]{2}{*}{ CV (\%) } \\
\hline & $0 \%$ & $8,5 \%$ & $19,5 \%$ & \\
\hline Matéria seca digestível (kg) & $5,0 \mathrm{a}$ & $4,5 \mathrm{ab}$ & $3,9 b$ & 8,9 \\
\hline Energia digestível (Mcal) & $22,7 \mathrm{a}$ & $22,8 a$ & $22,2 \mathrm{a}$ & 6,5 \\
\hline Extrato etéreo digestível (kg) & $0,3 c$ & $0,8 b$ & $1,2 \mathrm{a}$ & 5,7 \\
\hline FDN digestível (kg) & $2,1 \mathrm{a}$ & $1,7 \mathrm{~b}$ & $1,0 \mathrm{c}$ & 17,7 \\
\hline
\end{tabular}

Médias nas linhas, seguidas por letras iguais, não diferem pelo SNK $(P>0,05)$. 
O consumo de energia digestível não foi alterado $(\mathrm{P}>0,05)$ pela inclusão de óleo de soja nas dietas, provavelmente porque as dietas foram balanceadas para terem similar quantidade de energia digestível, de acordo com as exigências dos equinos, de 22,6 Mcal/dia (NRC, 1989). De acordo com Pagan (2000), a relação proteína:energia é fundamental nas dietas de equinos. Neste trabalho, os equinos consumiram dietas com relação de proteína bruta e energia digestível, em média de 41,6 g PB/Mcal ED, necessária à atividade esportiva.

\section{Conclusões}

A inclusão de óleo de soja nos níveis estudados pode ser feita em dietas para equinos atletas, pois possibilita a redução na quantidade do consumo dietético, aumenta a digestibilidade do extrato etéreo e reduz a digestibilidade aparente da celulose sem alterar a cinética da passagem da fase líquida da digesta no trato digestivo e a digestibilidade dos demais nutrientes.

\section{Literatura Citada}

ALMEIDA, F.Q.; VALADARES FILHO, S.C.; LEÃO, M.I. et al. Digestibilidade aparente pré-cecal, pós-ileal e total da proteína do milho e do farelo de soja em equinos. Revista Brasileira de Zootecnia, v.27, n.3, p.530-537, 1998.

ALMEIDA, M.I.V.; FERREIRA, W.M.; ALMEIDA, F.Q. et al. Composição química e predição do valor nutritivo de dietas para equinos. Revista Brasileira de Zootecnia, v.28, n.6, p.1268-1278, 1999.

BEYNEE A.C.; HALLEBEEK, J.M. High-fat diets for horses. In: EUROPEAN EQUINE NUTRITION AND HEALTH CONGRESS, 1., 2002, Netherlands. Proceedings... Netherlands. 2002. p.1-10.

BUSH, J.A.; FREEMAN, D.E.; KLINE, K. H. et al. Dietary fat supplementation effects on in vitro nutrient disappearance and in vivo nutrient intake and total tract digestibility by horses. Journal of Animal Science, v.79, p.232-239, 2001.

CUDDEFORD, D.; WOODHEAD, A.; MUIRHEAD, R.H. A. comparison between the nutritive value of short-cutting cycle, high temperature-dried alfalfa and timothy hay for horses. Equine Veterinary Journal, v.24, p.84-89, 1992.

CUNHA, T.J. Horse feeding and nutrition. 2.ed. San Diego: Academic Press, 1991. 445p.

DELOBEL, A.; FABRY, C.; SCHOONHEERE, N. et al. Linseed oil supplementation in diet for horses: Effects on palatability and digestibility. Livestock Science, v.116, p.15-21, 2008.

DROGOUL, C.; FOMBELLE, A.; JULLIAND, V. Feeding and a microbial disorders in horses: 2 - effect of three hay:grain ratios on digesta passage rate and digestibility in ponies. Journal of Equine Veterinary Science, v.21, n.10, p.487-491, 2001.

FAICHNEY, G.J. The use of markers to partition digestion within the gastrointestinal tract of ruminants. In: McDONALD, I.W., WARNER, A.I.C. (Ed.) Digestion and metabolism in ruminants. Armidale: University of New England Publishing Unit, 1975. p.277-291.

FRAPE, D. Equine nutrition and feeding. 3.ed. Victoria: Blackwell Publ., 2004. 650p.
HENNEKE, D.R.; POTTER, G.D.; KREIDER, J.L. et al. Relationship between condition score, physical measurements and body fat percentage in mares. Equine Veterinary Journal, v.15, n.4, p.897-903, 1983.

HINTZ, H.F. Alimentando o cavalo atleta. In: SIMPÓSIO INTERNACIONAL DO CAVALO DE ESPORTE, 1., 1997, Belo Horizonte. Anais... Belo Horizonte: UFMG/Escola de Veterinária, 1997. p.49-57.

HINTZ, H.F.; CYMBALUK, N.F. Nutrition of the horse. Annual Review of Nutrition, v.14, p.243-267, 1994.

HUGHES, S.J.; POTTER, G.D.; GREENE, T.W. et al. Adaptation of Thoroughbred horses in training to a fat supplemented diet. Equine Veterinary Journal, v.18, p.349-352, 1995.

JANSEN, W.L.; CONE, S.N.J.; GEELEN, M.M. et al. High fat intake by ponies reduces both apparent digestibility of dietary cellulose and cellulose fermentation by faeces and isolated caecal and colonic contents. Animal Feed Science and Technology, v.133, p.298-308, 2007.

JANSEN, W.L.; GEELEN, S.N.J.; VAN DER KUILEN, J. et al. Dietary soybean oil depresses the apparent digestibility of fiber in trotters when substituted for an iso-energetic amount of corn starch or glucose. Equine Veterinary Journal, v.34, n.3, p.302-305, 2002.

JANSEN, W.L.; VAN DER KUILEN, J.; GEELEN, S.N.J. et al. The effect of replacing nonstructural carbohydrates with soybean oil on the digestibility of fiber in trotting horses. Equine Veterinary Journal, v.31, n.1, p.27-30, 2000

JULEN, T.R.; POTTER, G.D.; GREENE, L.W. et al. Adaptation to a fat-supplemented diet by cutting horses. Journal of Equine Veterinary Science, v.15, n.10, p.436-440, 1995

KANE, E.; BAKER, J.P.; BULL, L.S. Utilization of a corn oil supplemented diet by the pony. Journal of Animal Science, v.48, n.6, p.1379-1384, 1979.

KRONFELD, D.S.; HOLLAND, J.L.; RICH, G.A. et al. Fat digestibility in Equus caballus follows increasing first-order kinetics. Journal of Animal Science, v.82, p.1773-1780, 2004

LEWIS, L.D. Equine clinical nutrition. 1.ed. Philadelphia: Willians \& Wilkins Ed., 1995. 587p.

LORENZO-FIGUERAS, M.; PRESTON, T.; OTT, E.A. et al. Mealinduced gastric relaxation and emptying in horses after ingestion of high-fat versus high-carbohydrate diets. American Journal Veterinary Research, v.66, n.5, p.897-906, 2005.

MANZANO, A.; WANDERLEY, R.C.; ESTEVES, S.N. Óleo de soja e gordura animal na alimentação de equinos. Revista Brasileira de Zootecnia, v.24, n.5, p.788-799, 1995.

MARQUEZE, A.; KESSLER, A.M.; BERNARDI, M.L. Aumento do nível de óleo em dietas isoenergéticas para cavalos submetidos a exercício. Ciência Rural, v.31, n.3, p.491-496, 2001.

MATTOS, F.; ARAÚJO, K.V.; LEITE, G.G. et al. Uso de óleo na dieta de equinos submetidos ao exercício. Revista Brasileira de Zootecnia, v.35, n.4, p.1373-1380, 2006.

NATIONAL RESEARCH COUNCIL - NRC. Nutrient requirements of horses. 5.ed.rev. Washington, D.C.: National Academies Press, 1989. 100p.

NATIONAL RESEARCH COUNCIL - NRC. Nutrient requirements of horses. 6.ed.rev. Washington, D.C.: National Academies Press, 2007. 341p.

OLIVEIRA, C.A.A. Digestibilidade de nutrientes e cinética de passagem da digesta em dietas com diferentes níveis de volumoso para equinos. 2001. 80f. Dissertação (Mestrado em Zootecnia) - Universidade Federal Rural do Rio de Janeiro, Seropédica, 2001

OLIVEIRA, C.A.A.; ALMEIDA, F.Q.; VIEIRA, A.A. et al. Cinética da passagem da digesta, balanço hídrico e de nitrogênio em equinos consumindo dietas com diferentes proporções de volumoso e concentrado. Revista Brasileira de Zootecnia, v.32, n.1, p.140-149, 2003. 
OLIVEIRA, K.; COSTA, C.; FAUSTINO, M.G. et al. Trânsito gastrintestinal e digestibilidade aparente de nutrientes em equinos alimentados com dietas contendo grãos secos ou silagem de grãos úmidos de triticale. Revista Brasileira de Zootecnia, v.36, n.6, p.1799-1808, 2007.

PAGAN, J.D. Protein requirements and digestibility: a review. In: PAGAN, J.D. (Ed.) Advances in equine nutrition 1. Lexington: Kentucky Equine Research, 2000. p.43-50.

PAGAN, J.D.; HARRIS, P.A.; BREWSTER-BARNES, T. et al. Exercise affects digestibility and rate of passage of all-forage and mixed diets in thoroughbreds horses. Journal of Nutrition, v.128, p.2704S-2707S, 1998.

PALMGREN KARLSSON, C.; LINDBERG, J.E.; RUNDGREN, M. Associative effects on total tract digestibility in horses fed different ratios of grass hay and whole oats. Livestock Production Science, v.65, p.143-153, 2000.

PIMENTEL, R.R.M.; ALMEIDA, F.Q.; VIEIRA, A.A. et al. Consumo, digestibilidade aparente dos nutrientes e balanço hídrico em equinos alimentados com feno de coast-cross em diferentes formas. Revista Brasileira de Zootecnia, v.38, n.7, p.1272-1278, 2009.

POTTER, G.D.; HUGHES, S.L.; JULEN, T.R. et al. A review of research on digestion and utilization of fat by the equine. Pferdeheilkunde, p.119-123, 1992 (suppl.).
RAMMERSTORFER, C.; POTTER, G.D.; CUDD, T.A. et al. Physiological responses of mature quarter horses to reining training when fed conventional and fat-supplemented diets. Journal of Equine Veterinary Science, v.18, n.3, p.175-183, 1998.

ROSTAGnO, H.S. Tabelas brasileiras para aves e suínos: composição de alimentos e exigências nutricionais. 2.ed. Viçosa, MG: Universidade Federal de Viçosa, 2005. 186p.

SALIBA, E.O.S.; PEREIRA, R.A.N.; FERREIRA, W.M. et al. Lignin from Eucaliptus grandis as indicator for rabbits in digestibility trials. Tropical and Subtropical Agroecosytems, v.3, n.1-3, 2003.

SILVA, D.J.; QUEIROZ, A.C. Análise de alimentos: métodos químicos e biológicos. 3.ed. Viçosa, MG: Universidade Federal de Viçosa, 2002. 235p.

UNIVERSIDADE FEDERAL DE VIÇOSA - UFV. Sistema de análises estatísticas e genéticas - SAEG. Versão 9.1. Viçosa, MG: Universidade Federal de Viçosa, 2007. 301p.

VAN SOEST, P.J.; ROBERTSON, J.B.; LEWIS, B.A. Methods of dietary fiber, neutral detergent fiber, and nonstarch polysaccharides in relation to animal nutrition. Journal of Animal Science, v.74, p.3583-3597, 1991.

VAN WEYENBERG, S.; SALES, J.; JANSSENS, G.P.J. Passage rate of digesta through the equine gastrointestinal tract: A review. Livestock Science, v.99, p.3-12, 2006. 